\title{
GENDER AND EQUITY IN E-LEARNING
}

\author{
J. Coldwell \\ Deakin University, Geelong, Australia \\ Email: jo.coldwell@deakin.edu.au
}

\section{A. Goold}

Deakin University, Geelong, Australia

Email: annegret.goold@deakin.edu.au

\section{A. Craig}

Deakin University, Geelong, Australia

Email: annemieke.craig@deakin.edu.au

\author{
J. Mustard \\ Deakin University, Geelong, Australia \\ Email: jamie.mustard@deakin.edu.au
}

\begin{abstract}
Literature to date suggests contrary indicators of acceptance of the use of technology to support learning by females. With the increasing adoption of information technology to support teaching and learning, it is imperative that factors which may impede student learning are identified. The research reported here is of a large-scale survey of the perceptions of university students about eLearning and their use of the online learning environment. The aim of the survey was to gather data to inform about online learning practices at the University. The results were explored, amongst other factors, by gender. Findings include no significant differences between the female and male students with respect to being able to use the online learning environment confidently and effectively. In general the female students were more willing to participate in online discussions. However, there was no difference between the female and male students regarding their willingness to voice their opinions online. An unexpected result was the greater value placed by female students on using the online environment for communicating and collaborating with students of diverse background.
\end{abstract}




\section{INTRODUCTION}

There is contradictory evidence in the literature as to the adoption and acceptance of information technologies by females. On the one hand, reports suggest that females are being disadvantaged by the introduction of information and communication technologies (ICT) in the learning arena. On the other, there is evidence that in some areas, females are more likely to have a positive experience of using technology. With the increased adoption of online learning technologies to support teaching and learning in higher education institutions, it is imperative that any factors which may impede student learning are identified with the aim of removing them. All learners should learn in environments that support their needs yet online learners are not a homogenous group (McGee 2002). The identification of possible gender inequities in online learning environments (OLEs) is the focus of this paper. As asserted by McGee (2002) whatever the reasons higher educational institutions have for delivering courses online, it is the student's success that is the desired outcome.

In the context of this research eLearning can be described as learning processes and interactions between students and teachers that are supported by information and communication technologies (ICT). The level of eLearning may range from static delivery of key documents to fully supported communication and collaboration online.

Higher education institutions are increasingly adopting online technologies to support teaching and learning and Deakin University is no exception. As part of the University's commitment to preparing students for lifelong learning, it has mandated that every student experience at least one wholly online unit as part of their undergraduate degree programme (Deakin University 2003). A wholly online unit is defined as one where there are no face-to-face classes at all, and all teaching and administrative support is provided through an OLE. A key objective of a wholly online unit is for students to develop skills in online communication and collaboration while studying the unit curriculum. Communication and the ability to work in virtual teams (collaboration) are seen as important lifelong learning skills. Online learning offers students a different type of learning experience. It can 'provide an educationally superior alternative to traditional lectures' and it can 'also provide a model for students on how to become self directed independent learners, which may assist them to become lifelong learners' (Singh et al. 2005).

Haywood et al. (2004) suggest the 'differential experience, confidence, or preparedness to participate, of any group must be considered as a potential source of discrimination and inequity' (p. 14 ) in online environments. There are numerous perspectives which may shed light on equity issues in education including culture, age, race, gender, and socio-economic status (Meyers et al. 2004). Meyers et al. (2004) suggest that it is 'from examining these diverse perspectives that the developing field of ICT in eLearning will most benefit' (p. 4). Such research can then provide the evidence base to inform the development of eLearning strategies in the educational context (Haywood et al. 2004).

Educators at Deakin University have supported eLearning for a number of years. The focus now is on improving the learning in these environments in an endeavour to ensure successful learning outcomes for all students. The University population is becoming more diverse, with increasing numbers of international students, and with local students having more varied skills and backgrounds. The factor of culture is having an increasing impact on teaching and learning, both in the traditional face-to-face classroom as well as the online virtual classroom.

The research presented in this paper was undertaken as part of a Strategic Teaching and Learning Grant at Deakin University in 2005. The overall aim of the larger study was to investigate the impact of cultural diversity in the OLE. The larger study involved a review of literature and data 
collection from academics involved with online teaching at Deakin University. The findings were then benchmarked with external experts. The final part of the study was a large scale online survey that was designed to gather the perceptions of the entire University student population about eLearning, online environments and cultural diversity.

This paper reports on particular outcomes from the student survey (2711 respondents). In the survey, students were asked to self assess their confidence and level of competence when using the OLE. They were also asked a number of questions about how they used and participated in discussion forums. The responses were analysed by culture, age and gender to determine whether there were any indications of differences in students' perceived level of confidence and competence in using the OLE. The results from the gender breakdown are reported here. In the discussion section, findings which support or contradict the literature are emphasised.

\section{BACKGROUND}

Over the last 20 years the tertiary education sector in Australia has changed dramatically in a number of ways. Overall more local students are attending tertiary institutions; there are more international students and the number of female students is increasing. During the first 130 years of tertiary education in Australia male students outnumbered female students (Maslen and Slattery 1994). Since the late 1980s however, female enrolments have exceeded male enrolments in the undergraduate population of universities, a situation mirrored at Deakin University with $57 \%$ of the student population being female (Deakin University 2006).

A large body of research exists on the male-dominated culture of computing (Craig 1996). Research from the 1980s and 1990s show that women are less enthusiastic about using and working with ICTs than men. These findings are reiterated in a recent the EDUCAUSE Survey (Katz 2006) which found that 'female respondents...prefer less technology in their courses than others'. The reasons for this are complex and include an array of factors which interact to produce the ICT experiences and outcomes for women (Craig 2005).

Kirkup (2002) suggests that, with a more diverse body of students attending university, finding ways to be inclusive of all through an electronic medium, will not be any easier than teaching in a face-to-face classroom. According to Kirkup (2002, p. 13) there is 'now a wealth of research on the gender differences of male and female online activity, all of which demonstrate the online environment creating a gendered world operating in similar ways to the material world'.

Observable changes are, however, apparent. From a study of 1200 students at Edinburgh University, Haywood et al. (2004) found for example, that a difference in the level of computer ownership between males and females was no longer statistically significant. They suggest that with regard to technology, the inequality of access and computer literacy has become a diminishing problem. Yet there is evidence to the contrary. In Trent and Slade's (2001) study for instance, they discovered that while $80 \%$ of the boys indicated that they mostly used computers at home, only $40 \%$ of the girls did the same. Huyer (2003, p. 120) suggests there needs to be 'more sex-disaggregated data collected at every level of implementation' of ICTs, to ensure that new applications such as online learning environments are inclusive of all students and that there is no differential impact on female or male students.

The introduction then of eLearning has prompted a new range of studies in gender-related issues. Many have focussed on particular aspects of the technologies used in OLEs and suggest that the online learning experience is different for female and male students (Gunn et al. 2003; Astleitner 
and Steinberg 2005). Factors that appear to impact on the online learning experience relate to confidence and having access to computers at home (Gunn et al. 2003). One area where gender differences continue to persist is in students' self confidence with the technology (Haywood et al. 2004). However the Gunn et al. (2003) study found that female students outperformed male students in an online web design unit and suggested that the issue was not a lack of confidence in the female students but rather an overestimation of confidence and ability by the male students who were therefore not putting in the necessary effort to perform well in the unit.

Many studies have targeted online discussion forums as an area for gender research. These studies have often focussed on small groups of students in case-study type research. The Meyers et al. study (2004) of mature-age rural women and the Giannini-Gachago and Seleka (2005) study of students in a Masters course from Botswana and the United States are examples here. In both of these studies there were perceived differences in the use of asynchronous communication, such as discussion boards, in online learning environments, by women compared with men. Consequently the researchers postulated that there were implications for the design and moderation of discussion forums in OLEs to ensure that they are fair and equitable arenas for all participants. According to an Open University UK survey 'female students appreciate the use of computer conferencing for contact with other students, course directors, and tutors, suggesting that women students may experience more support in an online environment' (Huyer 2003). Bissell et al. (2002) reported that only $58 \%$ of the men appreciated the computer conferencing compared to $82 \%$ of the women. Yet other researchers have identified only small gender differences in online discussions and activities (Kirkup 2002; Davidson-Shivers et al. 2003).

The literature therefore has indicated that this is an area where there are differences. The research reported here makes a significant contribution because of the large number of students involved in the study. Additionally, for these students, much of their learning took place through online communication. The study enables a direct comparison between both male and female students.

\section{METHODOLOGY}

Deakin University has five physical campuses, covering a capital city and regional areas, and has a strong history and extensive experience as a provider of distance education. Deakin has adopted a policy of teaching the same course on and off campus using technology to support delivery and interaction. Deakin is 'at the forefront of the convergence of distance and on campus teaching and learning through internet based technologies' (Evans and Stacey 2002). The provision of high quality online learning is a variant of the high quality distance learning that Deakin is known for.

In 2005 Deakin University had an enrolment of over 32,000 students across five faculties (Deakin University 2006). In a normal semester a full-time student would be expected to undertake four of some 1500 undergraduate or 700 postgraduate unit offerings. A standard three-year undergraduate programme is 24 units completed over six semesters.

Deakin Studies Online (DSO) is the acronym Deakin uses for its OLE. DSO incorporates a suite of integrated teaching and learning technologies including WebCT Vista (now known as Blackboard), eLive, iLecture and Turnitin. Additional tools such as Respondus, StudyMate and social software enhance the functionality and useability of the online teaching and learning environment. Every unit taught by Deakin has an online presence in DSO however each unit may vary in their level of onlineness. Some units that are taught in face-to-face mode may only have a basic online presence, with the unit outline and study materials available for downloading, and a discussion forum 
available for contact with teaching staff. At the other end of the scale are wholly online units in which all teaching takes place in the OLE and there is a heavy emphasis on communication and collaboration. In 2005 there were 23 nominated wholly online units at Deakin. These units represent core units in each of the five faculties and are part of Deakin University's commitment to preparing students for lifelong learning, thus ensuring that each student completes at least one wholly online unit during their degree program (Deakin University 2003).

The aim of the overall research study was to ascertain students' perceptions about their learning experience in the OLE. A survey questionnaire was deemed the most appropriate method of collecting the data. In the context of this research it was important to gather the opinions of a diverse range of students with the aim of obtaining a representative sample of the University population. According to Thomas (2004) representativeness means that what is learnt about the sample would be essentially the same if the entire population was included and thus generalizations can be made for the population as a whole.

The student survey questionnaire was posted on the University's Intranet in September 2005 and was made available to the entire University student population for a period of two weeks. The survey responses were anonymous and voluntary, in accordance with the University ethical guidelines.

The 60 questions on the questionnaire were developed by the researchers. The questions were based on issues highlighted in the literature and identified as likely to inform online learning practices.

The questions covered:

- $\quad$ demographics (age, gender, country of birth, language, cultural background);

- studies at Deakin (mode of study and enrolment, enrolled faculty, major area of study, experience with online units);

- $\quad$ perceptions of the OLE;

- $\quad$ perceptions of their ability to use the OLE;

- $\quad$ perceptions of virtual group work;

- $\quad$ perceptions of their role as a student; and

- expectations of learning generally, and of learning online.

Most of the questions required a five-point Likert scale response from strongly agree (1) to strongly disagree (5). A number of questions required open-ended responses. The data from the online survey was gathered into a spreadsheet and various types of statistical analyses were performed. For most of the questions listed above the results were broken down by gender and basic summary results were determined for females and males in the sample. Hypothesis tests for the difference between two population proportions were then performed to determine if the differences found between females and males in the sample were statistically significant; in other words, determine if the results found held for the entire University population. (All results are reported in the next section).

The literature suggested some key areas where similarities or differences between male and female students might be significant in online learning. These areas were the level of confidence and ability to effectively use the OLE, and the degree of student participation in the online discussion forums. Gunn (2003, p 24) suggests that the challenge is to 'identify the characteristics that make learning environments friendly to both male and female students' and then one is able to encourage participation by, and success for, all. 


\section{RESULTS}

The total student population at Deakin University in 2005 was 32,354 (Deakin University 2006). Table 1 shows the break-up of the students with respect to gender, mode of study and mode of enrolment.

The total number of completed surveys was 2711. Although this response rate is low, the rate is in line with a University-wide student evaluation survey done on WebCT Vista in Semester 1 2005. In that survey 2546 students responded and this was considered to be "adequate to provide reliable indicators” (Deakin University 2005). Of the 2711 surveys completed here, 10 were unusable and were therefore not included in the data analysis.

\begin{tabular}{|l|l|l|l|}
\hline \multicolumn{4}{|c|}{ Students enrolled in 2005} \\
N= 32,354 \\
\hline Male & $43 \%$ & Female & $57 \%$ \\
\hline Full-time & $59 \%$ & Part-time & $41 \%$ \\
\hline $\begin{array}{l}\text { On- } \\
\text { campus }\end{array}$ & $65 \%$ & $\begin{array}{l}\text { Off- } \\
\text { campus }\end{array}$ & $35 \%$ \\
\hline
\end{tabular}

Table 1: University population

\begin{tabular}{|l|l|l|l|}
\hline \multicolumn{4}{|c|}{$\begin{array}{c}\text { Survey data } \\
n=2701\end{array}$} \\
\hline Male & $39 \%$ & Female & $61 \%$ \\
\hline Full-time & $71.5 \%$ & Part-time & $28.5 \%$ \\
\hline $\begin{array}{l}\text { On- } \\
\text { campus }\end{array}$ & $69 \%$ & $\begin{array}{l}\text { Off- } \\
\text { campus }\end{array}$ & $31 \%$ \\
\hline
\end{tabular}

Table 2: Survey Population

Table 2 shows the break-up of the survey data. Gender, mode of study and mode of enrolment in the survey data indicated that the completed surveys were a representative sample of the 2005 student population (Table 1). There were only minor differences between the survey data and the reported University demographics in 2005. The survey data had a slightly higher representation of females (4\% more); students studying full-time (13\% more); and on-campus students (4\% more).

Table 3 shows the break-up of students by (owning) faculty for the University population as well as the survey sample. Again there were some minor differences in the response rates. Responses for students from the Arts and Education faculties were slightly lower while the response rates from the Health and Behavioural Science, and the Science and Technology students were higher. Interestingly, the proportion of Business and Law students responding to the survey was the same as their proportion of the University population. Again the minor differences are not significant. Overall there is reasonable confidence that the data collected from the survey data is representative of the University population as a whole, and are adequate to provide reliable measures of student perceptions. 


\begin{tabular}{|l|c|c|c|c|}
\hline \multicolumn{1}{|c|}{ Faculty } & \multicolumn{2}{c|}{ University Population } & \multicolumn{2}{c|}{ Survey Data } \\
\hline Arts & 6424 & $20 \%$ & 384 & $15 \%$ \\
\hline Health \& Behavioural Sciences & 4544 & $14 \%$ & 421 & $17 \%$ \\
\hline Business \& Law & 11803 & $37 \%$ & 926 & $37 \%$ \\
\hline Education & 4373 & $14 \%$ & 276 & $11 \%$ \\
\hline Science and Technology & 4864 & $15 \%$ & 474 & $19 \%$ \\
\hline
\end{tabular}

Table 3: Total Enrolment and Completed Survey by Faculty

\section{Overall confidence/effective use in OLE}

Students were asked whether they were confident in their use of DSO (the OLE). They were also asked whether they believed that they were able to make effective use of this environment. The majority of respondents (84\%) reported being confident in using DSO by selecting either agree or strongly agree (Table 4). Five percent of students stated that they were not confident in their use of DSO (disagree or strongly disagreed). The remainder (nearly 11\%) were unsure. Similarly the majority of students believed that they used DSO effectively (85\% agreed or strongly agreed) with only $5 \%$ believing that they were not able to use DSO effectively (Table 5).

To ascertain whether there were any differences between females and males in terms of confidence and effective use, students were divided by gender. Of the 1,646 female students who responded, $86 \%$ generally agreed when asked whether they were confident is using the OLE and $87 \%$ claimed they could use the OLE effectively. The corresponding percentages for the 1055 males who participated were $82 \%$ (for confidence) and $82 \%$ (for effective use). Female students were sightly more positive about their confidence and effectiveness in their use of the OLE than the male students. A hypothesis test for the difference between two population proportions was performed and although the difference in the sample is only slight, it is, nevertheless, statistically significant ( $z=2.84, p<0.01$ for confidence and $z=3.43, p<0.01$ for effective use).

\begin{tabular}{|l|l|l|l|}
\hline \multirow{2}{*}{$\begin{array}{c}\text { I am confident in } \\
\text { using DSO }\end{array}$} & \multicolumn{3}{|c|}{ Gender } \\
\cline { 2 - 4 } & $\mathrm{F}$ & \multicolumn{1}{|c|}{$\mathrm{M}$} & \multicolumn{1}{|c|}{ Total } \\
\hline Strongly Agree & $38.9 \%$ & $36.2 \%$ & $37.9 \%$ \\
\hline Agree & $47.0 \%$ & $45.7 \%$ & $46.5 \%$ \\
\hline Neutral & $10.0 \%$ & $11.9 \%$ & $10.8 \%$ \\
\hline Disagree & $2.3 \%$ & $3.4 \%$ & $2.7 \%$ \\
\hline $\begin{array}{l}\text { Strongly } \\
\text { Disagree }\end{array}$ & $1.6 \%$ & $2.7 \%$ & $2.0 \%$ \\
\hline Not Applicable & $0.1 \%$ & $0.1 \%$ & $0.1 \%$ \\
\hline Total & $100 \%$ & $100 . \%$ & $100 \%$ \\
\hline
\end{tabular}

Table 4: Confidence

\begin{tabular}{|l|c|c|c|}
\hline \multirow{2}{*}{$\begin{array}{l}\text { I am able to use } \\
\text { DSO Effectively }\end{array}$} & \multicolumn{3}{|c|}{ Gender } \\
\cline { 2 - 4 } & $\mathrm{F}$ & $\mathrm{M}$ & Total \\
\hline Strongly Agree & $36.6 \%$ & $31.5 \%$ & $34.6 \%$ \\
\hline Agree & $50.0 \%$ & $50.2 \%$ & $50.1 \%$ \\
\hline Neutral & $8.7 \%$ & $12.3 \%$ & $10.1 \%$ \\
\hline Disagree & $3.3 \%$ & $4.7 \%$ & $3.9 \%$ \\
\hline & & & \\
Strongly Disagree & $1.3 \%$ & $1.1 \%$ & $1.2 \%$ \\
\hline Not Applicable & $0.1 \%$ & $0.1 \%$ & $0.1 \%$ \\
\hline Total & $100 \%$ & $100 \%$ & $100 \%$ \\
\hline
\end{tabular}

Table 5: Effective Use

Apart from gender, participation at the start of the semester was found to be another important factor in determining levels of self confidence or effective use. Students were asked to indicate whether they took the time to explore DSO unit sites at the start of semester and 1,802 (67\%) of all students generally agreed. Of these students, approximately $90 \%$ were both confident and believed 
they used DSO effectively. Of the remaining students, only $73 \%$ were confident and $74 \%$ believed they used DSO effectively (see Table 6). These differences between the two groups are considerable and are clearly statistically significant $(z=11.87, p<0.01$ for confidence and $z=11.02, p<0.01$ for effective use).

\begin{tabular}{|c|c|c|c|c|c|c|c|}
\hline \multirow{2}{*}{$\begin{array}{c}\text { I am } \\
\text { confident } \\
\text { in using } \\
\text { DSO }\end{array}$} & \multicolumn{3}{|c|}{ Explore DSO at start of semester } & \multirow{2}{*}{$\begin{array}{l}\text { I am able to } \\
\text { use DSO } \\
\text { Effectively }\end{array}$} & \multicolumn{3}{|c|}{ Explore DSO at start of semester } \\
\hline & $\begin{array}{c}\text { Generally } \\
\text { agree }\end{array}$ & $\begin{array}{c}\text { Generally } \\
\text { disagree }\end{array}$ & Total & & $\begin{array}{c}\text { Generally } \\
\text { agree }\end{array}$ & $\begin{array}{c}\text { Generally } \\
\text { disagree }\end{array}$ & Total \\
\hline $\begin{array}{l}\text { Generally } \\
\text { agree }\end{array}$ & $90.2 \%$ & $72.6 \%$ & $84.4 \%$ & $\begin{array}{l}\text { Generally } \\
\text { agree }\end{array}$ & $90.1 \%$ & $73.9 \%$ & $84.7 \%$ \\
\hline $\begin{array}{l}\text { Generally } \\
\text { disagree }\end{array}$ & $3.6 \%$ & $7.5 \%$ & $4.9 \%$ & $\begin{array}{l}\text { Generally } \\
\text { disagree }\end{array}$ & $3.7 \%$ & $8.1 \%$ & $5.2 \%$ \\
\hline Neutral & $6.2 \%$ & $19.9 \%$ & $10.8 \%$ & Neutral & $6.2 \%$ & $18.0 \%$ & $10.1 \%$ \\
\hline Total & $100.0 \%$ & $100.0 \%$ & $100.0 \%$ & Total & $100.0 \%$ & $100.0 \%$ & $100.0 \%$ \\
\hline
\end{tabular}

Table 6: Explore DSO at start of semester

It is noteworthy that more females (70\%) compared to males (61\%) explored DSO at the start of the semester. This may explain in part the differences found between genders described above, but further study is required to confirm these findings.

\section{Participation in discussion forums}

About $45 \%$ of students indicated that they liked posting messages and participating in online discussion forums with $25 \%$ saying they disliked it and 30\% indicating that they neither liked nor disliked posting messages and participating in online discussions (Table 7).

\begin{tabular}{|l|c|c|c|}
\hline \multirow{2}{*}{$\begin{array}{c}\text { I DO NOT like } \\
\text { posting message } \\
\text { in DSO }\end{array}$} & \multicolumn{3}{|c|}{ Gender } \\
\cline { 2 - 4 } & $\mathrm{F}$ & $\mathrm{M}$ & Total \\
\hline Strongly Agree & $4.9 \%$ & $5.5 \%$ & $5.1 \%$ \\
\hline Agree & $19.0 \%$ & $20.9 \%$ & $19.7 \%$ \\
\hline Neutral & $28.1 \%$ & $31.7 \%$ & $29.5 \%$ \\
\hline Disagree & $37.2 \%$ & $29.8 \%$ & $34.3 \%$ \\
\hline $\begin{array}{l}\text { Strongly } \\
\text { Disagree }\end{array}$ & $10.0 \%$ & $11.1 \%$ & $10.4 \%$ \\
\hline Not Applicable & $0.8 \%$ & $1.1 \%$ & $0.9 \%$ \\
\hline Total & $100 \%$ & $100 \%$ & $100 \%$ \\
\hline
\end{tabular}

Table 7: Posting messages

\begin{tabular}{|c|c|c|c|}
\hline \multirow{2}{*}{$\begin{array}{l}\text { DSO Discussion } \\
\text { enable students to } \\
\text { help each other }\end{array}$} & \multicolumn{3}{|c|}{ Gender } \\
\hline & $\mathrm{F}$ & M & Total \\
\hline Strongly Agree & $25.1 \%$ & $18.3 \%$ & $22.4 \%$ \\
\hline Agree & $50.4 \%$ & $49.5 \%$ & $50.1 \%$ \\
\hline Neutral & $18.7 \%$ & $23.0 \%$ & $20.4 \%$ \\
\hline Disagree & $4.9 \%$ & $7.3 \%$ & $5.8 \%$ \\
\hline $\begin{array}{l}\text { Strongly } \\
\text { Disagree }\end{array}$ & $0.9 \%$ & $1.9 \%$ & $1.3 \%$ \\
\hline Not Applicable & $\begin{array}{l}100.0 \\
\%\end{array}$ & $100.0 \%$ & $100.0 \%$ \\
\hline Total & $100 \%$ & $100 \%$ & $100 \%$ \\
\hline
\end{tabular}

Table 8: Help each other

'Posting messages' was another important factor for effective use of DSO. The majority of students (76\%) who did NOT believe they used DSO effectively also disliked (or were neutral about) posting messages.

The female students were, in general, more willing to participate in the online discussion forums (Table 7 ) with $47 \%$ generally disagreeing to NOT liking posting messages compared to only $41 \%$ of males. The results are statistically significant $(z=3.27, p<0.01)$. Further to this, $75 \%$ of female students believed that they derived a benefit from students assisting each other in these forums, 
compared with only $68 \%$ of the male students (Table 8 ). The difference is again statistically significant $(z=4.40, p<0.01)$. There were also more female students $(50 \%)$ compared with male students (45\%) that selected communication via DSO as one of the advantages of the technology (Table 9).

\begin{tabular}{|c|c|c|c|}
\hline \multirow{2}{*}{$\begin{array}{c}\text { It is easy to } \\
\text { communicate } \\
\text { with others }\end{array}$} & \multicolumn{3}{|c|}{ Gender } \\
\cline { 2 - 4 } & $\mathrm{F}$ & $\mathrm{M}$ & Total \\
\hline No & $50.3 \%$ & $55.3 \%$ & $52.2 \%$ \\
\hline Yes & $49.7 \%$ & $44.7 \%$ & $47.8 \%$ \\
\hline Total & $100.0 \%$ & $100.0 \%$ & $100.0 \%$ \\
\hline
\end{tabular}

Table 9: Advantage of DSO

\begin{tabular}{|c|c|c|c|}
\hline \multirow{2}{*}{$\begin{array}{c}\text { Ask for help } \\
\text { when I'm } \\
\text { not sure }\end{array}$} & \multicolumn{3}{|c|}{ Gender } \\
\cline { 2 - 4 } & $\mathrm{F}$ & $\mathrm{M}$ & Total \\
\hline No & $13.4 \%$ & $24.6 \%$ & $17.8 \%$ \\
\hline Yes & $86.6 \%$ & $75.4 \%$ & $82.2 \%$ \\
\hline Total & $100.0 \%$ & $100.0 \%$ & $100.0 \%$ \\
\hline
\end{tabular}

Table 10: My role as a student

Perceptions of what students believed their role at University to be, were explored. Eighty-seven percent of the female students believed it was their role as a student to ask questions when they were unsure, yet only $75 \%$ of male students agreed (Table 10). This result is statistically significant $(z=7.44, p<0.01)$. In contrast, when asked if they would ask the teacher or other students for help, there was no discernable difference between the responses of male and female students $(z=1.24$, $p=0.21$ ). It is interesting to note that both males and females are less willing to ask other students for help compared with seeking help from their teachers (Tables 11 and 12).

\begin{tabular}{|c|c|c|c|}
\hline \multirow{2}{*}{$\begin{array}{c}\text { I am prepared to } \\
\text { ask the teacher } \\
\text { for help }\end{array}$} & \multicolumn{3}{|c|}{ Gender } \\
\cline { 2 - 4 } & $\mathrm{F}$ & $\mathrm{M}$ & Total \\
\hline Strongly Agree & $25.9 \%$ & $24.0 \%$ & $25.1 \%$ \\
\hline Agree & $48.6 \%$ & $48.4 \%$ & $48.5 \%$ \\
\hline Neutral & $19.3 \%$ & $19.3 \%$ & $19.3 \%$ \\
\hline Disagree & $5.5 \%$ & $7.4 \%$ & $6.2 \%$ \\
\hline $\begin{array}{c}\text { Strongly } \\
\text { Disagree }\end{array}$ & $0.7 \%$ & $0.9 \%$ & $0.8 \%$ \\
\hline Total & $100.0 \%$ & $100.0 \%$ & $100.0 \%$ \\
\hline
\end{tabular}

Table 11: Getting help from Staff

\begin{tabular}{|c|c|c|c|}
\hline \multirow{2}{*}{$\begin{array}{c}\text { I am prepared to } \\
\text { ask other } \\
\text { students for help }\end{array}$} & $\mathrm{F}$ & $\mathrm{M}$ & Total \\
\cline { 2 - 4 } & $22.3 \%$ & $20.7 \%$ & $21.7 \%$ \\
\hline Strongly Agree & $21 \%$ & $46.7 \%$ & $46.9 \%$ \\
\hline Agree & $47.1 \%$ & $23.0 \%$ & $22.2 \%$ \\
\hline Neutral & $21.6 \%$ & $8.9 \%$ & $8.3 \%$ \\
\hline Disagree & $8.0 \%$ & & \\
\hline $\begin{array}{c}\text { Strongly } \\
\text { Disagree }\end{array}$ & $1.0 \%$ & $0.7 \%$ & $0.9 \%$ \\
\hline Total & $100.0 \%$ & $100.0 \%$ & $100.0 \%$ \\
\hline
\end{tabular}

Table 12: Getting help from each other

\section{Voicing Opinions in discussion forums}

Overall students claimed that they are willing to voice their opinions on DSO. Fifty-two percent agreed or strongly agreed and only $17 \%$ disagreed or strongly disagreed (Table 13). There was no significant difference between the responses of male and female students $(z=1.10, p=0.27)$. Voicing an opinion does not seem to influence whether or not a student perceives themselves as an effective user of the DSO technology. 


\begin{tabular}{|c|c|c|c|}
\hline \multirow{2}{*}{$\begin{array}{l}\text { I am willing to voice } \\
\text { my opinion in } \\
\text { discussions in DSO }\end{array}$} & \multicolumn{3}{|c|}{ Gender } \\
\hline & $\mathrm{F}$ & M & Total \\
\hline Strongly Agree & $13.0 \%$ & $10.9 \%$ & $12.2 \%$ \\
\hline Agree & $40.2 \%$ & $40.1 \%$ & $40.1 \%$ \\
\hline Neutral & $28.9 \%$ & $31.1 \%$ & $29.7 \%$ \\
\hline Disagree & $14.3 \%$ & $14.7 \%$ & $14.5 \%$ \\
\hline Strongly Disagree & $2.3 \%$ & $2.0 \%$ & $2.2 \%$ \\
\hline Not Applicable & $1.3 \%$ & $1.2 \%$ & $1.3 \%$ \\
\hline Total & $100.0 \%$ & $100.0 \%$ & $100.0 \%$ \\
\hline
\end{tabular}

Table 13: Voicing an opinion

Not surprisingly most of the students who were not willing to express their opinions also did not like posting messages. However, there was a small number (14\%) of those students who did not express their opinions that did enjoy posting messages. Tables 14, 15 and 16 show that when split by gender, the results indicate that there is practically no difference between the opinions of males and females.

\begin{tabular}{|c|c|c|c|}
\hline \multirow{2}{*}{$\begin{array}{c}\text { My role as a student: } \\
\text { Express my opinion }\end{array}$} & \multicolumn{3}{|c|}{ Gender } \\
\cline { 2 - 4 } & $\mathrm{F}$ & $\mathrm{M}$ & Total \\
\hline No & $33.2 \%$ & $34.2 \%$ & $33.6 \%$ \\
\hline Yes & $66.8 \%$ & $65.8 \%$ & $66.4 \%$ \\
\hline Total & $100.0 \%$ & $100.0 \%$ & $100.0 \%$ \\
\hline
\end{tabular}

Table 14: My role is to express my opinion

\begin{tabular}{|c|c|c|c|}
\hline \multirow{2}{*}{$\begin{array}{l}\text { Disadvantage of DSO: } \\
\text { My opinions are not } \\
\text { heard }\end{array}$} & \multicolumn{3}{|c|}{ Gender } \\
\hline & $\mathrm{F}$ & M & Total \\
\hline No & $95.3 \%$ & $92.1 \%$ & $94.0 \%$ \\
\hline Yes & $4.7 \%$ & $7.9 \%$ & $6.0 \%$ \\
\hline Total & $100.0 \%$ & $100.0 \%$ & $100.0 \%$ \\
\hline
\end{tabular}

Table 15: In DSO my opinions are not heard 


\begin{tabular}{|c|c|c|c|}
\hline \multirow{2}{*}{$\begin{array}{c}\text { Disadvantage of DSO: } \\
\begin{array}{c}\text { Some students } \\
\text { dominate when online }\end{array}\end{array}$} & $\mathrm{F}$ & $\mathrm{M}$ & Total \\
\cline { 2 - 4 } & $74.1 \%$ & $75.3 \%$ & $74.5 \%$ \\
\hline No & $25.9 \%$ & $24.7 \%$ & $25.5 \%$ \\
\hline Yes & $100.0 \%$ & $100.0 \%$ & $100.0 \%$ \\
\hline Total & & & \\
\hline
\end{tabular}

Table 16: In DSO some students dominate

\section{Collaboration with others}

Students were asked whether they thought it was valuable to work with students from diverse backgrounds in the OLE. While $81 \%$ of the female students agreed or strongly agreed with this statement, only $70.3 \%$ of the male students were in agreement (Table 17). This is a statistically significant difference with $z=6.45, p<0.01$.

\begin{tabular}{|c|c|c|c|}
\hline $\begin{array}{c}\text { I think it is valuable to work with students } \\
\text { from diverse backgrounds }\end{array}$ & \multicolumn{3}{|c|}{ Gender } \\
\hline & $\mathrm{F}$ & $\mathrm{M}$ & Total \\
\hline Strongly Agree & $37.5 \%$ & $31.2 \%$ & $35.1 \%$ \\
\hline Agree & $43.5 \%$ & $39.1 \%$ & $41.8 \%$ \\
\hline Neutral & $17.4 \%$ & $25.1 \%$ & $20.4 \%$ \\
\hline Disagree & $1.5 \%$ & $4.0 \%$ & $2.5 \%$ \\
\hline Strongly Disagree & $0.1 \%$ & $0.7 \%$ & $0.3 \%$ \\
\hline Total & $100.0 \%$ & $100.0 \%$ & $100.0 \%$ \\
\hline
\end{tabular}

Table 17: Working with others from diverse backgrounds

A curious result, not necessarily of importance to gender research is that whereas $90.8 \%$ of the females have the expectation that they should submit work which is their own, only $82.7 \%$ of males have a similar expectation. It should be of concern to all academics that almost $18 \%$ of males and $9 \%$ of females do NOT have such an expectation!

\section{Nationality}

Nationality and culture of students, and the influences these factors have on students and their use of DSO, were part of the larger study as described in the Introduction. The detailed results about nationality are to be reported elsewhere. For completeness, we note here that there are considerable variations between students of different nationalities and their use of DSO. In particular, those students from Asian countries compared to other countries show the most prominent differences; students from Asian countries tended to be less confident about using DSO, did not like posting messages and did not consider themselves to be effective users of DSO, compared with local 
students and students of other nationalities. The most relevant part of these results here is that the impact of gender appears to be independent of nationality.

\section{DISCUSSION}

\section{Overall confidence/effective use in OLE}

The literature (Gunn et al. 2003, Haywood et al. 2004) had suggested that the main areas for possible discrepancies between male and female students could be in the areas of confidence and effective use of the OLE and students' level and type of participation in the online discussion forums. Females often rate themselves as being less competent and having less experience with the Internet (Gunn et al. 2003) and consistently underestimate their technology skills regardless of what their skills really are (Sanders 2005). The results of our study are contrary to this earlier literature. There is a statistically significant difference between female and male students with more females being confident in using the OLE and more believing they effectively use the technology.

Several explanations for this are possible. The majority of students 1487 (55\%) indicated that they had completed a wholly online unit; 917 (34\%) were female and 570 (21\%) were male. In wholly online units all teaching takes place in the OLE and students are exposed to a wide range of online technologies. One would expect that students who had completed a wholly online unit would be confident about using the OLE and making effective use of it. The relatively higher number of female students who responded and who considered that they had completed online units could have skewed the results here. Other explanations are possible. For example the imperative to use the OLE may well have had a positive impact on females' attitudes towards the OLE, impacting on their perceived confidence and effectiveness.

\section{Participation in discussion forums}

At the Open University in the UK (as cited in Huyer 2003) 82\% of females appreciate computer conferencing compared with $58 \%$ of men; $91 \%$ of females used web resources compared with $50 \%$ of men. These findings align themselves with Gunn where the possibility that 'male students may be over-confident in their ability and think they do not have to put in as much effort to meet the course requirements' (Gunn et al. 2003) is presented.

The results of our research are in agreement with the earlier literature. Enjoying posting messages in the OLE and being willing to participate is an important factor in determining whether a student is confident and can use the OLE effectively. There are (statistically) more females than males willing to participate and also more who list the communication aspect of the OLE as an advantage.

Perceptions of what students believed their role at University to be, were explored. Eighty-seven percent of the female students believed it was their role as a student to ask questions when they were unsure, yet only $75 \%$ of male students agreed (Table 10). This may suggest that male students expect to have all details of the learning materials provided, or for some other reason, are not prepared to ask when they are unsure. In contrast, when asked if they would ask the teacher or other students for help, there was no discernable difference between the responses of male and female students but slightly fewer students overall are willing to ask other students for help compared to asking their teachers (Tables 11 and 12).

Some research (Gferer and Pauschwein. 2002; Bissell et al. 2002, as cited in Huyer 2003) suggested that the anonymity afforded by online environments suits females allowing them to work to their 
maximum competence. In a study of ICT-based lectures at the FH-Joanneum in Austria 'female students tend to appreciate the privacy of virtual education, with no pressure or fear of appearing stupid in front of male students' (Huyer 2003, p. 118). The literature also suggests that females are better at communication than males. This skill may outweigh any perceived shortcomings in technical skills in the OLE, increasing female's perception of their competence.

The differences described above, in communication via an OLE, did not extend to voicing opinions over the OLE. There was no significant difference between females and males in terms of expressing opinions. Thus it is possible that the greater use in communication by females in the OLE has improved the willingness of female students to express their opinions such that there is now no significant difference between genders. However, further research would be required to confirm this.

Further investigation is also required in two other areas. Firstly, female students appeared to perceive their role as students to be different from male students. However this is not straightforward as the results are mixed. Secondly, the area of female students valuing the ability to work with people from diverse backgrounds much more highly is of interest and warrants further in-depth study.

\section{Limitations}

A limitation of the study is that the sample was non random. As the survey was conducted in the OLE, students who were not comfortable in participating online may have chosen not to participate. Conversely those who were more active online may have participated because they felt comfortable in doing so.

\section{CONCLUSIONS}

Hiltz and Turoff (2005) suggest that as online learning environments are no longer confined to tertiary institutions but are beginning to appear in K-12, adult learning and corporate training, it is imperative that these environments are suitable and inclusive of all students. Because of this wide spread and growing use, it is important that all students are comfortable with OLEs and can use the technology effectively. This study has found, in higher education at least, that such environments were generally used confidently by all groups of students, regardless of a students' gender or study mode.

Another finding of our study suggests that female students are not disadvantaged by the use of ICTs in the learning environment as they have a similar perceived level of confidence and effectiveness in using the OLE as males, as well as being willing to participate in the online environment. The findings support the assertions in Astleitner and Steinberg (2005, p.60) who suggest that 'the gender gap in technology-related education like web-based learning begins to close'. It is important to note however that this study does not contradict other studies which have identified numerous gender differences in areas such as learning styles, communication patterns or participation barriers.

Finally, it was clear that students who actively explored the OLE early in the semester had greater self confidence and were more effective users. Consequently it is recommended that all students should be encouraged to immerse themselves in the OLE early in their course as this will contribute to their ultimate success.

Unlike many of the studies reported in the literature, our study had a very large base, the sample being representative of the University student population. The findings disagree with some of those 
reported in the literature. In depth investigation is required to confirm or refute these findings as well as to explore the discrepancies in the perceived roles between the genders and the conundrum of female communication skills versus male technical skills.

\section{REFERENCES}

Astleitner H. and Steinberg, R. (2005). Are There Gender Differences in Web-Based Learning? An Integrated Model and Related Effect Sizes. AACE Journal, Vol. 13(1), pp 47-63.

Bissell, C., Chapman, D., Herman, C. and Robinson, L. (2002). Some Gender Issues in the Teaching of Information and Communication Technologies at the UK Open University. In Improving the Gender Balance in Engineering Education Using ICT Methods and Contents. Oulu Polytechnic, Institute of Technology and University of Oulu, Faculty of Technology, Oulu, Finland.

Campbell, K. (2000). Gender and Educational Technologies: relational frameworks for learning design. Journal of Educational Multimedia and Hypermedia. Vol 9(1), pp.131-149.

Craig, A. (1996). Encouraging Female Students in Business Computing. Masters Thesis, Victoria University of Technology.

Craig, A. (2005). Girls Not Choosing Computing: Causes and Effects. Redress, Journal of The Association of Women Educators, Vol. 14(3), pp 2 - 7.

Davidson-Shivers, G. V., Morris, S. B. and Sriwongkol T. (2003). Gender Differences: Are They Diminished in Online Discussions? International Journal on E-Learning, Vol. 2(1), pp 29-36.

Deakin University (2003). Online technologies in courses and units - operational policy. Accessed last on $24^{\text {th }}$ January 2006 at http://theguide.deakin.edu.au/TheDeakinGuide.nsf/Web+Visitors?OpenFrameSet\& Frame= WebContent\&Src $=$ WI2.1 ?penPage \&Choice $=0 \&$ Access $=$ Visitor

Deakin University (2005) DSO (WebCT Vista) Evaluation Report: semester 1, 2005. Internal report.

Deakin University (2006) 2005 Pocket Statistics. Planning Unit, Accessed last July 2006 at http://www.deakin.edu.au/planning-unit/statistics/pocket/2005.php

Evans, T., and Stacey, E. (2002) Flexible learning for Quality in Higher Education. Proceedings of EDU-COM 2002, Higher Education without Borders. Sustainable Development in Higher Education, Khon Kaen, Thailand, 25-27 November

Gferer, M. and Pauschwein, J. (2002). Is the Change from Traditional Teaching Methods to ICTBased Methods Going to Attract More Female Students to Study Engineering? An Analysis of ICT-Based Lectures at the FH-Joanneum. In Improving the Gender Balance in Engineering Education Using ICT Methods and Contents. Oulu Polytechnic, Institute of Technology and University of Oulu, Faculty of Technology, Oulu, Finland.

Giannini-Gachago, D. and Seleka, G. (2005). Experiences with international online discussions: Participation patterns of Botswana and American students in an Adult Education and Development course at the University of Botswana. International Journal of Education and Development using ICT, Vol. 1(2). 
Gunn, C., McSporran, M., MacLeod, H. and French, S. (2003). Dominant or Different? Gender Issues in Computer Supported Learning. Journal of Asynchronous Learning Networks, Vol. $7(1)$, pp $14-30$.

Haywood, J., MacLeod, H., Haywood, D., Mogey, N. and Alexander, W. (2004). The Student View of ICT in Education at the University of Edinburgh: skills, attitudes \& expectations. In Association for Learning Technologies. Exeter.

Hiltz, S. R. and Turoff, M. (2005). Education goes digital: The Evolution of Online Learning and the Revolution in Higher Education. Communications of the ACM, Vol. 48(10), pp 59-64.

Huyer, S. (2003). Gender, ICT, and Education. Engendering ICT. World Bank, pp 100 -124.

Jones, L. (2005). Maintaining the Curricular Philosophies of a Multicultural Education Course: from face-to-face to eLearning environments. AACE Journal. Vol 13(1), pp.91-99.

Katz, R. N. (2006). The ECAR study of undergraduate students and information technology, 2006. Educause Center for Applied Research. Accessed last on 20 September 2007 at http://www.educause.edu/ir/library/pdf/EKF/EKF0607.pdf.

Kirkup, G. (2002). ICT as a tool for enhancing women's education opportunities; and new educational and professional opportunities for women in new technologies. Seoul, Republic of Korea, United Nations Division for the Advancement of Women (DAW), Expert Group Meeting on "Information and communication technologies and their impact on and use as an instrument for the advancement and empowerment of women", pp 1-15.

Maslen, G. and Slattery, L. (1994). Why our Universities are failing. Melbourne, Wilkinson Books, Information Australia.

McFarlane, A. Bradburn, A. and McMahon, A. (2003) E-Learning for Leadership: Emerging indicators of effective practice. National College for School Leadership, Autumn 2003. Accessed last on 12 June 2007 from http://www.ncsl.org.uk/media/F7B/98/randd-litreview-e-learning-full.pdf

McGee, P. (2002) Web-Based Learning Design: Planning for Diversity. United States Distance Learning Association Journal Vol 16(3) Accessed last on 12 June 2007 from http://www.usdla.org/html/journal/MAR02_Issue/article03.html

Meyers, W., Bennett, S. and Lysaght, P. (2004). Asynchronous communication: Strategies or equitable e-learning. In Beyond the comfort zone: Proceedings of the 21st ASCILITE Conference. (Eds: Atkinson, R., McBeath, C., Jonas-Dwyer, D. and Phillips, R.), Perth, pp. 655-662.

Sanders, J. (2005). Gender and Technology: What the Research Tells Us, Women and ICT, Baltimore MD, June, 2005.

Singh, G., O'Donoghue, J. and Worton, H. (2005). A study into The Effects Of eLearning On Higher Education. Journal of University Teaching and Learning Practice Vol. 2 (2), pp 13-24.

Thomas, S. J. (2004). Using web and paper questionnaires for data-based decision making: From design to interpretation of the results, Corwin Press, Thousand Oaks, California.

Trent, F. and Slade, M. (2001) Declining Rates of Achievement and Retention. The perception of adolescent males. Evaluations and Investigations Programme, Higher Education Division. Department of Education, Training and Youth Affairs. The Flinders University of South Australia 
